\title{
Adverse effects of a modified regime of intravenous desferrioxamine
}

\author{
M P Senanayake ${ }^{1}$, W D J de Silva ${ }^{2}$, S P Lamabadusuriya ${ }^{3}$ \\ Sri Lanka Journal of Child Health, 2001; 30: 41-3
}

(Key words: Intravenous desferrioxamine, adverse effects)

\begin{abstract}
The aim of this study was to investigate the side effects to intravenous desferrioxamine in a cohort of thalassaemic patients receiving $100 \mathrm{mg} / \mathrm{kg} / \mathrm{day}$ of desferrioxamine on 3 consecutive days coinciding with blood transfusions on a long term basis. The patients studied were aged 7-22 yrs and the duration of desferrioxamine therapy exceeded one year.
\end{abstract}

Hypersensitivity in the form of urticaria occurred in one patient and was controlled with prednisolone. None of the patients complained of visual or auditory symptoms. The non thalassaemic control population were not on desferrioxamine, and did not have similar ocular or auditory changes. Six of the study population (mean age 9.3 years) had lens opacities. Abnormal audiograms were present in eight (mean age $10 \mathrm{yrs}$ ). The mean ages and the duration of the desferrioxamine therapy of patients with abnormalities was higher than the patients in whom no abnormalities were found.

We conclude that the risk of ocular and auditory toxicity increased with duration of desferrioxamine therapy.

We recommend monitoring for visual and audiometric changes despite the absence of symptoms even in patients receiving less than the total recommended dose of intravenous desferrioxamine

\section{Introduction}

Desferrioxamine, the only available iron chelator until recently, is still widely used in the management of thalassaemic patients in Sri Lanka. Side effects are considered to be minimal and its main disadvantages are the high cost and cumbersome route of administration.

${ }^{1}$ Senior Lecturer in Paediatrics, University of Colombo, ${ }^{2}$ Registrar, Lady Ridgeway Hospital, Colombo, ${ }^{3}$ Senior Professor of Paediatrics, University of Colombo.
Hypersensitivity to this drug is rare and local reactions of pain, swelling and itching seldom occurred after the intramuscular route had been abandoned. Ocular and auditory abnormalities have been reported with high doses of subcutaneous and intravenous desferrioxamine $e^{1,2,3}$.

Due to the unavailability of subcutaneous infusion pumps many centers in Sri Lanka continue to use the intravenous route.

Financial constraints necessitated us to use a modified regime of $100-120 \mathrm{mg} / \mathrm{kg}$ body weight/day of desferrioxamine on three consecutive days by the intravenous route to patients with beta thalassaemia major. The three doses coincided with monthly blood transfusions. The aim of this study was to determine the toxic effects of this modified intravenous regime of desferrioxamine.

\section{Study design}

A prospective observational study.

\section{Study population}

Thirty one transfusion dependant patients with beta thalassaemia major, aged 7-22 years comprised the study group. All patients were treated with long term desferrioxamine. 30 apparently healthy non thalassaemic persons of similar age and sex, served as controls.

\section{Study setting}

University Unit, Lady Ridgeway Childrens' Hospital Colombo.

\section{Method}

Adverse reactions to desferrioxamine were noted during a one year period from January to December 1992. The entire study population underwent ophthalmic, audiometric and radiological assessment. The ophthalmic examination included assessment of visual acuity, colour vision, intra ocular pressure, slit lamp examination and funduscopy following full dilatation of pupils. Conventional headphone 
audiometry was carried out on all patients and those with abnormal audiograms were assessed for middle ear disease by an ear nose and throat surgeon. Radiographic evidence of eighth cranial nerve compression was looked for in the study group with per orbital $\mathrm{x}$-ray views of the skull.

\section{Results}

One patient aged 7 years developed generalised urticaria needing bolus doses of prednisolone at $2 \mathrm{mg} / \mathrm{kg} / \mathrm{day}$ at each intravenous desferrioxamine infusion to abate the symptoms. Urticaria was not related to blood transfusions.

Photophobia, night blindness or other visual symptoms were not present in the study population. Ophthalmic assessment showed bilateral punctate, discrete lens opacities in six subjects and macular mottling in one. The lens opacities did not affect visual acuity. A 22 year old female, the oldest in the cohort studied, had a well defined unilateral cataract.

Hearing loss or tinnitus had not been experienced by any of the study group. Audiometry showed a mild sensorineuronal loss at low frequencies (range of 250$500 \mathrm{hz}$ ) in six patients, and at high frequencies (20004000 hertz) in two patients. Middle ear disease was absent in all eight patients with abnormal audiograms.

Both eye and hearing abnormalities were present in three patients. The control group did not have any ocular or auditory abnormalities.

All patients with ocular or auditory changes had received desferrioxamine for a period of at least four years. Table 1 shows that the mean duration of iron chelation and the mean ages of the patients with ocular abnormalities and/or hearing defects were greater than the patients in whom there were no such abnormalities detected.

\begin{tabular}{|c|c|c|c|}
\hline \multicolumn{4}{|c|}{$\begin{array}{l}\text { Table } 1 \text { Adverse effects of a modified } \\
\text { regimen of intravenous desferrioxamine }\end{array}$} \\
\hline & $\begin{array}{c}\text { Numb } \\
\text { of } \\
\text { patier } \\
(n=3\end{array}$ & $\begin{array}{l}\text { Mean } \\
\text { age } \\
\text { (yrs) }\end{array}$ & $\begin{array}{c}\text { Duration of } \\
\text { desferrioxamine } \\
\text { (yrs) }\end{array}$ \\
\hline \multicolumn{4}{|l|}{ Ocular toxicity } \\
\hline Presen & 7 & 9.3 & 7.5 \\
\hline $\begin{array}{l}\text { Absent } \\
\text { Hearing loss }\end{array}$ & 24 & 7 & 5 \\
\hline Present & 8 & 10 & 7.4 \\
\hline Absent & 23 & 7.5 & 5.2 \\
\hline $\begin{array}{l}\text { Ocular }+ \text { hearing } \\
\text { abnormalaties }\end{array}$ & 3 & 14.3 & 9.5 \\
\hline
\end{tabular}

Radiological evidence of bone encroachment of the auditory canal was not found. However the possibility of eighth cranial nerve compression cannot be completely excluded radiologically.

\section{Discussion}

Allergic reactions to desferrioxamine are very rare but desensitisation had been effective ${ }^{4}$. Continuation of chelation therapy was possible with the use of prednisolone cover in the patient who developed allergy in our series. Lens opacities and sensorineuronal deafness have been described with both intravenous and subcutaneous regimes of desferrioxamine $e^{1,2,3}$. In our study these adverse effects, occurred even with the lesser quantity of drug administered. These findings were significant since none of the age and sex matched controls had similar abnormalities.

Davies et al have shown a statistically significant relationship between desferrioxamine and ocular and auditory abnormalities ${ }^{2}$. The reported abnormalities include lens opacities, decreased acuity, peripheral field loss, abnormal colour vision, defective dark adaptation, thinning of retinal vessels and retinal mottling. The audiological abnormality reported is tinnitus and high frequency sensorineuronal loss. The risk of adverse effects are reported to be higher when the iron burden is low ${ }^{5}$.

The exact pathogenesis of neurotoxicity of desferrioxamine has not been explained. Although it has been postulated that iron toxicity per se may cause these changes, the signs of ocular siderosis are very different to the changes found in these patients ${ }^{6}$. The iron burden is reported to be significantly lower in patients with eye and ear abnormalities because they have had more iron chelation with desferrioxamine. The deposition of desferrioxamine itself, or its interference with iron dependant enzyme activity are possible mechanisms. The chelation of a critical trace element such as aluminium or copper is also a possibility ${ }^{7,8}$.

Withdrawal of desferrioxamine is known to reverse or reduce these changes ${ }^{5}$.

However our patients were iron over loaded and desferrioxamine was the mainstay of therapy. Hence treatment was not withheld. Instead we plan to keep these patients under close supervision with regard to the development of symptoms and worsening of the signs. 
In our series abnormalities were encountered when the duration of iron chelation exceeded four years. It is noteworthy that ocular and auditory nerve toxicity were present with the reduced amount of intravenous desferrioxamine administered, and that these patients were asymptomatic. Based on these findings we recommend regular audio-visual monitoring of all patients on desferrioxamine therapy, since the absence of symptoms did not exclude ocular or auditory nerve toxicity. Monitoring is especially warranted when the duration of treatment exceeds four years.

\section{Acknowledgement}

We thank Dr. R Abeywickrama, Consultant ENT Surgeon, Lady Ridgeway Hospital, Colombo Drs. U. Mendis and H.C.N Fonseka Consultant Opthalmic Surgeons, Eye Hospital Colombo and Dr. I. N. A. Goonaratne, Consultant Radiologist, Lady Ridgeway Hospital Colombo for their invaluable assistance.

\section{References}

1. Olivieri N F, Bruncie J R, Chew E. Visual and auditory neurotoxicity in patients receiving subcutaneous desferrioxamine in fusions. $N \mathrm{Engl}$ J Med 1994, 314: 869-73.

2. Davies S C, Hungerford J L, Arden G B, Marcus R E, Miller M H, Huehns E R. Ocular toxicity of high dose intravenous desferrioxamine. Lancet 1983; 23: 181-4.
3. Borgna-Pignatti C, De Stefano P, Broglia A M. Visual loss in patient on high-dose subcutaneous desferrioxamine. Lancet 1984; 681.

4. Miller K B, Rosenwasser J L, Bessette J A M, Beer D J, Rocklin R E. Rapid desensitisation for desferrioxamine anaphylactic reaction. Lancet 1981; 91: 1059 .

5. Kanno H, Yamanobe S, Rybak L P. Ototoxicity of deferrioxamine. Amer. J. Otolaryngiology 1995; 16 (3): 148-52.

6. Wise JB. Treatment of experimental siderosis bulbi, vitreous haemorrhage and corneal blood staining with desferri-oxamine. Arch Opthal 1966; 75: 698-707.

7. Pall H, Blake D R, Winyard P. Ocular toxicity of desferrioxamine - an example of copper promoted autooxidative damage? $\mathrm{Br} J$ Opthalmol 1989; 73: 42-7.

8. De Virgiliis S, Congia M, Turco MP, et al. Depletion of trace elements and acute ocular toxicity induced by desferrioxamine in thalassaemics. Arch Dis Child 1988; 63: 250-5. 
